\title{
Guía de Práctica Clínica para el manejo de pacientes con Leucemia Linfoblástica Aguda en el Seguro Social del Perú (EsSalud)
}

\section{Clinical practice guideline for the management of patients with acute lymphoblastic leukemia in Peruvian Social Security (EsSalud)}

Correspondencia

Raúl Timaná-Ruiz

rtimanar@gmail.com

Recibido: 07/07/2020

Arbitrado por pares

Aprobado: 03/12/2020

Citar como: Macciota Felices B, Morón Corales C, Luna Matos M, Gonzales Madrid V, Melgarejo Moreno A, Zafra-Tanaka JH, et al. Guía de Práctica Clínica para el manejo de pacientes con Leucemia Linfoblástica Aguda en el Seguro Social del Perú (EsSalud). Acta Med Peru. 2021;38(1):64-78. doi: https://doi.org/10.35663/ amp.2021.381.1038
Ninoska Rojas Soto', Mariela Moreno Larrea'1, Marlies Pizarro Perea', Lourdes Aranda Gomero', Cecilia Arteta Altamirano², Renee Eyzaguirre Zapata ${ }^{3}$, Sergio GoicocheaLugo4, Wendy Nieto- Gutierrez ${ }^{4}$, Franko O. Garcia-Solorzano5, Alvaro Taype-Rondan4, Raúl Timaná Ruiz ${ }^{4}$

1. Hospital Nacional Edgardo Rebagliati Martins. Seguro Social de Salud (EsSalud). Lima, Perú.

2. Hospital Nacional Alberto Sabogal Sologuren. Seguro Social de Salud (EsSalud). Lima, Perú.

3. Hospital Nacional Guillermo Almenara Irigoyen. Seguro Social de Salud (EsSalud). Lima, Perú.

4. Instituto de Evaluación de Tecnologías en Salud e Investigación - IETSI. Seguro Social de Salud (EsSalud). Lima, Perú

5. Universidad Ricardo Palma (URP). Lima, Perú.

\section{RESUMEN}

El presente artículo resume recomendaciones clínicas basadas en evidencia para la evaluación y el manejo de pacientes con Leucemia Linfoblástica Aguda (LLA) en EsSalud. Se conformó un grupo elaborador de la guía (GEG) que incluyó médicos especialistas y metodólogos. El GEG formuló 8 preguntas clínicas a ser respondidas por la presente GPC. Se realizó búsquedas sistemáticas de revisiones sistemáticas y -cuando fue considerado pertinente- estudios primarios en PubMed y CENTRAL durante el 2019. Se seleccionó la evidencia para responder cada una de las preguntas clínicas planteadas. La certeza de la evidencia fue evaluada usando la metodología Grading of Recommendations Assessment, Development, and Evaluation (GRADE). En reuniones de trabajo periódicas, el GEG usó la metodología GRADE para revisar la evidencia y formular las recomendaciones, los puntos de buenas prácticas clínicas y el flujograma de evaluación y manejo. La presente GPC abordó 8 preguntas clínicas, divididas en cuatro temas: diagnóstico, medidas generales, manejo quimioterápico de LLA, y trasplante. En base a dichas preguntas se formuló 5 recomendaciones ( 3 recomendaciones fuertes y 2 recomendaciones condicionales), 20 puntos de buena práctica clínica, y 3 flujogramas.

Palabras claves: Leucemia Linfoblástica Aguda; Guía de práctica clínica; Enfoque GRADE; Medicina Basada en Evidencias (Fuente: DeCS BIREME). 


\section{ABSTRACT}

This paper summarizes the evidence-based clinical recommendations for the assessment and management of patients with acute lymphoblastic leukemia (ALL) in Peruvian Social Security (EsSalud). A guide writing team (GWT) was convened, which included specialized physicians and methodologists. The GWT asked 8 clinical questions to be responded by the Clinical Practice Guidelines (CPG). Detailed searches of systematic reviews and - when it was considered as pertinent - primary studied featured in PubMed and CENTRAL during 2019 were performed. Evidence for responding each of the proposed clinical questions was selected. Certainty of the evidence was determined using the Grading of Recommendations Assessment, Development, and Evaluation (GRADE) methodology. In scheduled workshops, the GWT used the GRADE methodology for reviewing the evidence and propose recommendations, the points for good clinical practice, and the assessment and management flowcharts. This CPG worked on 8 clinical questions, which were divided in 4 topics: diagnosis, general measures, chemotherapy management for ALL, and transplantation. On the basis of these questions, 5 recommendations were formulated ( 3 strong recommendations and 2 conditional recommendations), 20 points for good clinical practice, and 3 flow charts.

Keywords: Acute Lymphoblastic Leukemia, clinical practice guideline, GRADE, evidence-based medicine (Source: MeSH).

\section{INTRODUCCIÓN}

La leucemia linfoblástica aguda (LLA) es una neoplasia hematológica maligna caracterizada por el aumento de linfoblastos en la sangre y médula ósea ${ }^{[1]}$, que afecta principalmente a la población pediátrica y a adultos mayores de 60 años ${ }^{[2]}$.

A nivel mundial, se estima que la incidencia de LLA oscila entre 1 a 5 casos por 100000 habitantes ${ }^{[3]}$, siendo mayor en la región de las Américas, sobre todo en Costa Rica y Colombia ${ }^{[4]}$. En Perú, se han reportado 1679 casos de neoplasias hematológicas en la población pediátrica, entre los años 2006 y 2011, con una incidencia esperada en niños menores de 14 años de 270 a 360 nuevos casos por año ${ }^{[5,6]}$.

El acceso a intervenciones eficaces y el uso óptimo de los protocolos de tratamiento ha permitido elevar la supervivencia de pacientes con LLA hasta alrededor del 70 al $100 \%{ }^{[7,8]}$, principalmente debido a una disminución de la mortalidad asociada a infecciones y recaídas ${ }^{[9,10]}$. Sin embargo, en Perú se han reportado supervivencias menores ${ }^{[11,12]}$.

Debido a la importancia de este tema en términos de mortalidad y morbilidad, la Dirección de Guías de Práctica Clínica, Farmacovigilancia y Tecnovigilancia del Instituto de Evaluación de Tecnologías en Salud e Investigación (IETSI) del Seguro Social del Perú (EsSalud) elaboró la guía de práctica clínica (GPC) basada en evidencias para el diagnóstico y manejo de LLA, cuyas recomendaciones (Tabla 1 ) serán aplicadas por profesionales de la salud en EsSalud. El presente artículo es un resumen de dicha GPC.

\section{METODOLOGÍA}

El procedimiento seguido para la elaboración de la presente GPC está detallado en su versión "in extenso", la cual puede descargarse de la página web del IETSI de EsSalud (http://www. essalud.gob.pe/ietsi/guias_pract_clini.html). En resumen, se aplicó la siguiente metodología:

\section{Conformación del grupo elaborador de la guía local (GEG)}

Se conformó un GEG, que incluyó metodólogos y médicos especialistas en hematología.

\section{Formulación de preguntas}

En concordancia con los objetivos y alcances de esta GPC, el GEG formuló ocho preguntas clínicas (Tabla 1), cada una de las cuales pudo tener una o más preguntas PICO (Population, Intervention, Comparator, Outcome). A su vez, cada pregunta PICO pudo tener uno o más desenlaces (o outcomes) de interés.

\section{Búsqueda y selección de la evidencia}

Para cada pregunta PICO, se realizó la búsqueda y selección de la evidencia. Para ello, durante el 2019 se buscaron revisiones sistemáticas (RS) publicadas como artículos científicos (mediante búsquedas sistemáticas en PubMed y CENTRAL) o realizadas como parte de una GPC previa (mediante una búsqueda sistemática de GPC sobre el tema) (Material Suplementario 1). Cuando se encontraron RS de calidad aceptable, se escogió una RS para la toma de decisiones, la cual fue actualizada cuando el GEG lo consideró necesario. Cuando no se encontró ninguna RS de calidad aceptable, se realizó una búsqueda de novo de estudios primarios.

\section{Evaluación de la certeza de la evidencia}

La certeza de la evidencia para cada desenlace de cada pregunta PICO pudo ser alta, moderada, baja, o muy baja (Tabla 2). Para evaluar la certeza de la evidencia, se siguió la metodología de Grading of Recommendations Assessment, Development, and Evaluation (GRADE) ${ }^{[13]}$ y se usaron tablas de perfiles de evidencias de GRADE (Material Suplementario 2). Finalmente, se le asignó a cada recomendación el nivel de certeza más bajo alcanzado por sus desenlaces críticos. 
Tabla 1. Lista completa de recomendaciones

Pregunta 1: En niños (1 a 14 años) con leucemia linfoblástica aguda, ¿qué protocolo de manejo se debería usar?

BPC-1.1

En niños (1 a 14 años) con LLA, utilizar el protocolo Berlín-Frankfurt-Münster Intercontinental 2009 (ALL IC-BFM 2009) para el manejo quimioterapéutico de esta neoplasia.

En niños (1 a 14 años) con LLA, respecto a la estratificación de riesgo de los pacientes:

- Realizar la estratificación inicial de riesgo utilizando los criterios del protocolo ALL IC-BFM 2009.

\begin{tabular}{|c|c|c|}
\hline \multicolumn{3}{|c|}{ Estratificación inicial según ALL IC-BFM 2009} \\
\hline Riesgo estándar (SR) & Riesgo intermedio (IR) & Riesgo alto (HR) \\
\hline $\begin{array}{l}\text { - Edad de } 1 \text { a } 5 \text { años } \\
\text { y } \\
\text { - Conteo de leucocitos < } \\
20000 / \text { uL } \\
\text { y } \\
\text { - Conteo de blastos < 1000/uL } \\
\text { al día } 8\end{array}$ & $\begin{array}{l}\text { - Edad } \geq 6 \text { años o Conteo de } \\
\text { leucocitos } \geq 20000 / u L \\
\text { y } \\
\text { - Conteo de blastos }<1000 / u L \\
\text { al día } 8\end{array}$ & $\begin{array}{l}\text { - Traslocación 9;22 } \\
\text { - Traslocación 4;11 } \\
\text { o } \\
\text { - Conteo de blastos } \geq 1000 / \mathrm{uL} \text { al } \\
\text { día } 8 \\
\text { o } \\
\text { - Hipodiploidía } \leq 44 \text { cromosoma }\end{array}$ \\
\hline
\end{tabular}

BPC-1.2

- Re-estratificar el riesgo durante el transcurso de la quimioterapia utilizando la evaluación de la Enfermedad Mínima Residual (EMR), según el protocolo Italian Association of Pediatric Hematology Oncology BerlínFrankfurt-Münster 2009 (AIEOP-BFM 2009).

- Se definirá EMR positiva con los siguientes puntos de corte en los días 15, 33 y 78 de haber iniciado el manejo:

\begin{tabular}{l|ccc} 
& \multicolumn{3}{c}{ Días de evaluación de la EMR } \\
\cline { 2 - 4 } & En el día 15 & En el día 33 & En el día 78 \\
\hline EMR positiva & $\geq 0.1 \%$ & $\geq 0.01 \%$ & $\geq 0.01 \%$
\end{tabular}

EMR: Enfermedad Mínima Residual, expresado en porcentaje de blastos en por cada 10 mil células en médula ósea.

- Utilizar los siguientes valores de EMR en los días 15, 33 y 78 de haber iniciado el tratamiento, para reestratificar el grupo de riesgo:

\begin{tabular}{|lccc|}
\hline & \multicolumn{3}{c|}{ Días de evaluación de la EMR } \\
\cline { 2 - 4 } Re-estratificación según EMR & En el día 15 & En el día 33 & En el día 78 \\
\hline Riesgo estándar (SR) & $<0.1 \%$ & $<0.01 \%$ & $<0.01 \%$ \\
\hline Riesgo intermedio (IR) & $0.1 \mathrm{a}<10 \%$ & $0.01 \mathrm{a}<0.1 \%$ & $0.01 \mathrm{a}<0.1 \%$ \\
\hline Riesgo alto (HR) & $\geq 10 \%$ & $\geq 0.1 \%$ & $\geq 0.1 \%$ \\
\hline
\end{tabular}


En niños (1 a 14 años) con LLA, utilizar las indicaciones de trasplante de precursores hematopoyéticos de médula ósea basadas en los protocolos ALL IC-BFM 2009 y AIEOP-BFM 2009:

Indicaciones de trasplante de precursores hematopoyéticos de médula ósea en niños, adolescentes y adultos jóvenes; basadas en los protocolos ALL IC-BFM 2009 y AIEOP-BFM 2009.

BPC-1.4

- Pacientes que no logran remisión completa al día 33 y tienen enfermedad mínima residual mayor a $0.1 \%$ al día 33

- Traslocación 4;11 o MLL/AF4

- Hipodiploidía menor de 44 cromosomas o índice de ADN menor de $0.8 \%$

- Pobre respuesta a la prednisona y linaje tipo T o pro-B

- Pobre respuesta a la prednisona y conteo de leucocitos mayor a 100 000/uL en sangre periférica

- Pacientes con cromosoma Filadelfia positivo o BCR/ABL

- Pacientes clasificados como alto riesgo con M3 al día 15 por citometría de flujo

- Enfermedad mínima residual mayor o igual a $0.1 \%$ al día 72

Remisión completa: porcentaje de blasto en médula ósea al día 33 es menor a 5\%; Pobre respuesta a la prednisona: presencia de $\geq 1000$ blastos/ul en sangre periférica al día 8; Buena respuesta a la prednisona: presencia de $<1000$ blastos/ul en sangre periférica al día 8; M3: Porcentaje de blastos mayor o igual a $25 \%$ en médula ósea.

Pregunta 2: En adolescentes y adultos jóvenes (15 a 35 años) con leucemia linfoblástica aguda, ¿qué protocolo de manejo se debería usar?

Rec-2.1

En adolescentes y adultos jóvenes (15 a 35 años) con LLA, recomendamos utilizar un protocolo "pediátrico" en vez de un protocolo "para adultos" para el manejo quimioterapéutico de esta neoplasia.

\section{Recomendación: Fuerte Certeza: muy baja}

BPC-2.1 En adolescentes y adultos jóvenes (15 a 35 años) con LLA, utilizar el protocolo ALL IC-BFM 2009 para el manejo quimioterapéutico de esta neoplasia.

BPC-2.2 En adolescentes y adultos jóvenes (15 a 35 años) con LLA, respecto a la estratificación de los pacientes, seguir los puntos de buena práctica clínica propuestos para el manejo de niños (1 a 14 años).

BPC-2.3

En adolescentes y adultos jóvenes (15 a 35 años) con LLA, evaluar la EMR utilizando el método de citometría de flujo.

BPC-2.4

En adolescentes y adultos jóvenes (15 a 35 años) con LLA, utilizar las indicaciones de trasplante de precursores hematopoyéticos de médula ósea basados en los protocolos ALL IC-BFM 2009 y AIEOP-BFM 2009, mencionados en como punto de buena práctica clínica para el manejo de niños (1 a 14 años).

BPC-2.5

En algunos casos particulares, considerar extender el uso del protocolo ALL IC-BFM 2009 a adultos de 35 a 40 años con LLA dependiendo del estado general del paciente y del criterio del médico tratante.

Pregunta 3: En adultos (36 a 60 años) y adultos mayores (61 a más años) con leucemia linfoblástica aguda, ¿qué protocolo de manejo se debería usar?

BPC-3.1

En adultos (36 a 60 años) con LLA, utilizar el protocolo del Programa Español para el Tratamiento de las Hemopatías Malignas (PETHEMA) con código de protocolo LAL-19, para el manejo quimioterápico de esta neoplasia. 
En adultos (36 a 60 años) con LLA, respecto a la evaluación de la EMR:

- Utilizar los puntos de corte propuestos por el protocolo PETHEMA LAL-19 para decidir la conducta terapéutica a brindar de la siguiente manera:

BPC-3.2

\begin{tabular}{|c|c|c|c|}
\hline \multicolumn{4}{|c|}{ Conducta terapéutica según EMR en el protocolo PETHEMA LAL-19 } \\
\hline \multirow[b]{2}{*}{$\begin{array}{l}\text { Aspectos que } \\
\text { considerar }\end{array}$} & \multicolumn{3}{|c|}{ Momento de evaluación } \\
\hline & $\begin{array}{l}\text { Al final de la } \\
\text { inducción-1 en } \\
\text { aquellos pacientes que } \\
\text { recibieron dicha fase }\end{array}$ & $\begin{array}{l}\text { Al final de la consolidación precoz } \\
\text { de tres bloques más reinducción } \\
\text { en aquellos pacientes que } \\
\text { recibieron dichas fases }\end{array}$ & $\begin{array}{c}\text { Al final de la consolidación } \\
\text { de un bloque en aquellos } \\
\text { pacientes que recibieron } \\
\text { dicha fase }\end{array}$ \\
\hline EMR & $\geq 0.01 \%$ & $\geq 0.001 \%$ & $\geq 0.01 \%$ \\
\hline $\begin{array}{l}\text { Conducta } \\
\text { terapéutica }\end{array}$ & Brindar inducción-2 & $\begin{array}{c}\text { Brindar trasplante alogénico de } \\
\text { progenitores hematopoyéticos } \\
\text { en vez de quimioterapia de } \\
\text { mantenimiento }\end{array}$ & $\begin{array}{l}\text { Brindar inmunoterapia } \\
\text { previo al trasplante } \\
\text { alogénico de progenitores } \\
\text { hematopoyéticos }\end{array}$ \\
\hline
\end{tabular}

- Evaluar la EMR utilizando el método de citometría de flujo.

En adultos (36 a 60 años) con LLA, utilizar las indicaciones de trasplante de precursores hematopoyéticos de médula ósea del protocolo PETHEMA LAL-19:

- Paciente con EMR $\geq 0.001 \%$ al final de la fase de consolidación precoz más reinducción.

BPC-3.3 Paciente que alcanzó la remisión completa y EMR $<0.01 \%$ al final de la inducción-1, tiene genética desfavorable y culmina la fase de consolidación de un bloque.

- Paciente que recibió inducción-2 y culminó la fase de consolidación de un bloque.

- Paciente con LLA de linaje pre-T que culmina los tres bloques de consolidación.

BPC-3.4

En adultos mayores (61 años a más) con LLA que sean considerados candidatos para el manejo quimioterapéutico, utilizar el protocolo del PETHEMA para el Tratamiento de la Leucemia Linfoblástica Aguda con cromosoma Filadelfia negativo en pacientes de edad avanzada (PETHEMA LAL-07 OLD) para el manejo de esta neoplasia.

Pregunta 4: En pacientes con leucemia linfoblástica aguda, ¿cuándo debería realizarse la primera punción lumbar para diagnóstico de infiltración al sistema nervioso central y profilaxis?

BPC-4.1

En pacientes con LLA sin síntomas neurológicos sugestivos de infiltración, realizar la primera punción lumbar para evaluar la infiltración al sistema nervioso central (SNC) y brindar la primera terapia intratecal entre los días uno al siete luego de haber iniciado la prefase con prednisona. Posteriormente, en caso de no encontrar infiltración al SNC, las restantes Terapias Intra Tecales (TIT) profilácticas se realizarán los días 15 y 33.

BPC-4.2

En pacientes con LLA con síntomas neurológicos sugestivos de infiltración, realizar la primera punción lumbar para el diagnóstico de infiltración al sistema nervioso central el primer día en que se inicia la prefase con prednisona.

Pregunta 5: En pacientes con leucemia linfoblástica aguda con riesgo intermedio 0 alto que se encuentren en fase de consolidación temprana con el protocolo ALL IC-BFM 2009, ¿se debería utilizar el protocolo IB de intensidad aumentada o el de intensidad estándar?

En pacientes de 1 a 14 años con LLA de riesgo intermedio o alto que se encuentren en fase de consolidación temprana con el protocolo ALL IC-BFM 2009, sugerimos utilizar el protocolo IB de intensidad estándar en vez

Rec-5.1 del protocolo IB de intensidad aumentada

\section{Recomendación: Condicional Certeza: muy baja}

En pacientes de 15 a más años con LLA de riesgo intermedio o alto que se encuentren en fase de consolidación temprana con el protocolo ALL IC-BFM 2009, recomendamos utilizar el protocolo IB de intensidad estándar

Rec-5.2 en vez del protocolo IB de intensidad aumentada.

Recomendación: Fuerte

Certeza: Muy baja 
Pregunta 6: En pacientes con leucemia linfoblástica aguda de linaje B con riesgo intermedio que se encuentren en fase de consolidación con el protocolo ALL IC-BFM 2009, ¿qué dosis de metotrexato se debería administrar?

BPC-6.1

En pacientes con LLA de linaje B con riesgo intermedio que se encuentren en fase de consolidación con el protocolo ALL IC-BFM 2009, administrar $5000 \mathrm{mg} / \mathrm{m}^{2}$ de metrotexato.

Pregunta 7: En pacientes con leucemia linfoblástica aguda y cromosoma Filadelfia positivo $(\mathrm{Ph}+)$, ¿se debería brindar el Inhibidor de la Tirosina-Cinasa (TKI) imatinib?

En pacientes de 1 a 18 años con LLA y Ph+, recomendamos administrar el TKI Imatinib desde la confirmación de la presencia de $\mathrm{Ph}+$.

Rec-7.1

\section{Recomendación: Fuerte Certeza: Muy baja}

BPC-7.1

En pacientes de 1 a 18 años con LLA y Ph+, administrar Imatinib a dosis de $340 \mathrm{mg} / \mathrm{m}^{2} /$ día por vía oral de manera conjunta a la quimioterapia.

BPC-7.2

En pacientes de 18 a más años con LLA y Ph+, administrar Imatinib a dosis de 600 a $800 \mathrm{mg} /$ día por vía oral de manera conjunta a la quimioterapia.

Pregunta 8: En pacientes con LLA en remisión completa candidatos a trasplante de células madre hematopoyéticas, en los que no se encuentra disponible el trasplante alogénico emparentado idéntico ¿Se debería brindar trasplante alogénico no emparentado o trasplante haploidéntico?

En pacientes con LLA en remisión completa candidatos a trasplante de progenitores hematopoyéticos en los que no se encuentra disponible el trasplante alogénico emparentado idéntico, sugerimos brindar trasplante alogénico haploidéntico o no emparentado teniendo en cuenta la condición clínica, el balance de riesgo y

Rec-8.1 beneficios para cada paciente, y la disponibilidad de recursos logísticos.

\section{Recomendación: Condicional Certeza: Muy baja}

En pacientes con LLA en remisión completa candidatos a trasplante de progenitores hematopoyéticos,

BPC-8.1 en los que no se encuentra disponible el trasplante alogénico emparentado idéntico, el esquema de acondicionamiento previo al trasplante (mieloablativo o de intensidad reducida) dependerá de la condición clínica del paciente y el criterio del médico tratante.

BPC-8.2

En pacientes con LLA en remisión completa candidatos a trasplante de progenitores hematopoyéticos, en los que no se encuentra disponible el trasplante alogénico emparentado idéntico, brindar ciclofosfamida a dosis de $50 \mathrm{mg} / \mathrm{kg} /$ día durante dos días para la depleción de células T posterior al trasplante haploidentico.

* Número de recomendación (Rec) y de punto de buena práctica clínica (BPC)

\section{Formulación de las recomendaciones}

El GEG revisó la evidencia seleccionada para cada pregunta clínica en reuniones periódicas, y formuló recomendaciones fuertes o condicionales (Tabla 2) usando la metodología GRADE [14]. Para ello, se tuvo en consideración: 1) Beneficios y daños de las opciones, 2) Valores y preferencias de los pacientes, 3) Aceptabilidad por parte de los profesionales de salud, 4) Factibilidad de las opciones en los establecimientos de salud de EsSalud, y 5) Uso de recursos. Luego de discutir estos criterios para cada pregunta, el GEG formuló las recomendaciones por consenso o por mayoría simple. Asimismo, el GEG formuló puntos de buenas prácticas clínicas (BPC), usualmente en base a su experiencia clínica.

\section{Revisión por expertos externos}

La presente GPC fue revisada en reuniones con médicos especialistas representantes de otras instituciones y tomadores de decisiones. Asimismo, su versión in-extenso fue enviada por vía electrónica a expertos externos para su revisión (mencionados en la sección de agradecimientos). El GEG tuvo en cuenta los resultados de estas revisiones para mejorar las recomendaciones finales.

\section{Aprobación de la GPC}

La presente GPC fue aprobada para su uso en EsSalud, con Resolución N²3-DGPCFyT-IETSI-ESSALUD-2019 
Tabla 2. Significado de los niveles de certeza de la evidencia y de la fuerza de la recomendación

\section{Significado}

\begin{tabular}{cl|}
\hline $\begin{array}{c}\text { Certeza de la evidencia } \\
(\oplus \oplus \oplus \oplus) \\
\text { Alta }\end{array}$ & Es muy probable que el verdadero efecto sea similar al efecto estimado. \\
\hline $\begin{array}{c}(\oplus \oplus \oplus \bigcirc) \\
\text { Moderada }\end{array}$ & $\begin{array}{l}\text { Es moderadamente probable que el verdadero efecto sea similar al efecto estimado, pero es posible } \\
\text { que sea sustancialmente diferente }\end{array}$ \\
\hline $\begin{array}{c}(\oplus \oplus \bigcirc)) \\
\text { Baja }\end{array}$ & $\begin{array}{l}\text { Nuestra confianza en el efecto es limitada. El verdadero efecto podría ser sustancialmente diferente } \\
\text { al efecto estimado }\end{array}$ \\
\hline $\begin{array}{c}\text { M } \\
\text { Muy baja }\end{array}$ & $\begin{array}{l}\text { Nuestra confianza en el efecto es pequeña. El verdadero efecto probablemente sea } \\
\text { sustancialmente diferente al efecto estimado }\end{array}$ \\
\hline Fuerza de la recomendación & \\
\hline Recomendación fuerte & $\begin{array}{l}\text { El GEG considera que todos o casi todos los profesionales que revisan la evidencia disponible seguirín } \\
\text { esta recomendación. En la formulación de la recomendación se usa el término "se recomienda" }\end{array}$ \\
\hline Recomendación & $\begin{array}{l}\text { El GEG considera que la mayoría de los profesionales que revisan la evidencia disponible seguirían } \\
\text { esta recomendación, pero un grupo de profesionales podría optar por no aplicarlas en alguna } \\
\text { población particular, siempre que sea justificado. En la formulación de la recomendación se usa el } \\
\text { término "se sugiere" }\end{array}$ \\
\hline
\end{tabular}

\section{Actualización de la GPC}

La presente GPC tiene una validez de tres años. Al acercarse al fin de este período, se procederá a realizar una RS de la literatura para su actualización, luego de la cual se decidirá si se actualiza la presente GPC o se procede a realizar una nueva versión.

\section{RECOMENDACIONES}

La presente GPC abordó ocho preguntas clínicas, en relación con cuatro temas: diagnóstico, medidas generales, manejo quimioterápico de LLA, y trasplante. En base a dichas preguntas se formuló cinco recomendaciones (tres recomendaciones fuertes y dos recomendaciones condicionales), 20 puntos de buena práctica clínica, y tres flujogramas (Tabla 1 y Figuras 1-3).

La presente GPC se enfoca en los pacientes con diagnóstico de LLA de uno a más años. Para el manejo de esta neoplasia, el médico deberá decidir qué protocolo de manejo usar (Preguntas 1, 2 y 3); el día que se evaluará la presencia de infiltración al sistema nervioso central (Pregunta 4); qué tipo de protocolo IB usar durante la fase consolidación (Pregunta 5); la dosis de metotrexato que se va a administrar (Pregunta 6); si usar inhibidores de la Tirosina-Cinasa en pacientes con cromosoma Filadelfia positivo (Pregunta 7); y el tipo de trasplante (Pregunta 8).

A continuación, se expondrán las recomendaciones y los puntos de BPC para cada pregunta, así como un resumen del razonamiento seguido para llegar a cada uno de estos. Para ello, se usarán los códigos de cada recomendación y punto de BPC definidos en la Tabla 1.
Pregunta 1: En niños (1 a 14 años) con leucemia linfoblástica aguda, ¿qué protocolo de manejo se debería usar?

La búsqueda realizada no encontró evidencia de calidad para responder a esta pregunta. Por ello, se formuló puntos de BPC.

BPC-1.1: Los protocolos de manejo para pacientes con LLA son un conjunto de lineamientos usados para definir la clasificación de riesgo y el tratamiento de los pacientes ${ }^{[15]}$. Estos protocolos varían entre sí, en sus criterios de clasificación de riesgo, el uso de quimioterápicos, la intensidad y frecuencia de los regímenes, y en las indicaciones de trasplante. En la actualidad, existen varios protocolos pediátricos disponibles, entre los más conocidos se encuentran los del grupo Berlin-FrankfutMünster (BFM) ${ }^{[16]}$. El GEG consideró elegir usar el protocolo ALL IC-BFM 2009 del grupo BFM ${ }^{[17]}$, tomando en cuenta que es una actualización del protocolo ALL IC-BFM $2002{ }^{[18]}$, que fue validado en la población latinoamericana y reportó un alto porcentaje de supervivencia (82\%) y baja toxicidad (5\%); y que es un protocolo en el que se tiene experiencia de uso a nivel nacional.

BPC-1.2: Se ha encontrado que los pacientes con enfermedad mínima residual (EMR) negativa tienen mejor supervivencia global y supervivencia libre de eventos a los 10 años en comparación con los pacientes con EMR positivo ${ }^{[17]}$. Si bien el protocolo elegido ALL IC-BFM 2009 sugiere evaluar la EMR para realizar la estratificación de riesgo del paciente, sólo incluye la estratificación de riesgo por EMR el día 15. Debido a la necesidad de una reevaluación continua en nuestro contexto, se consideró utilizar los criterios del protocolo AIEOP-BFM 2009 que incluye la evaluación de la EMR en el día 15, 33 y 78. 


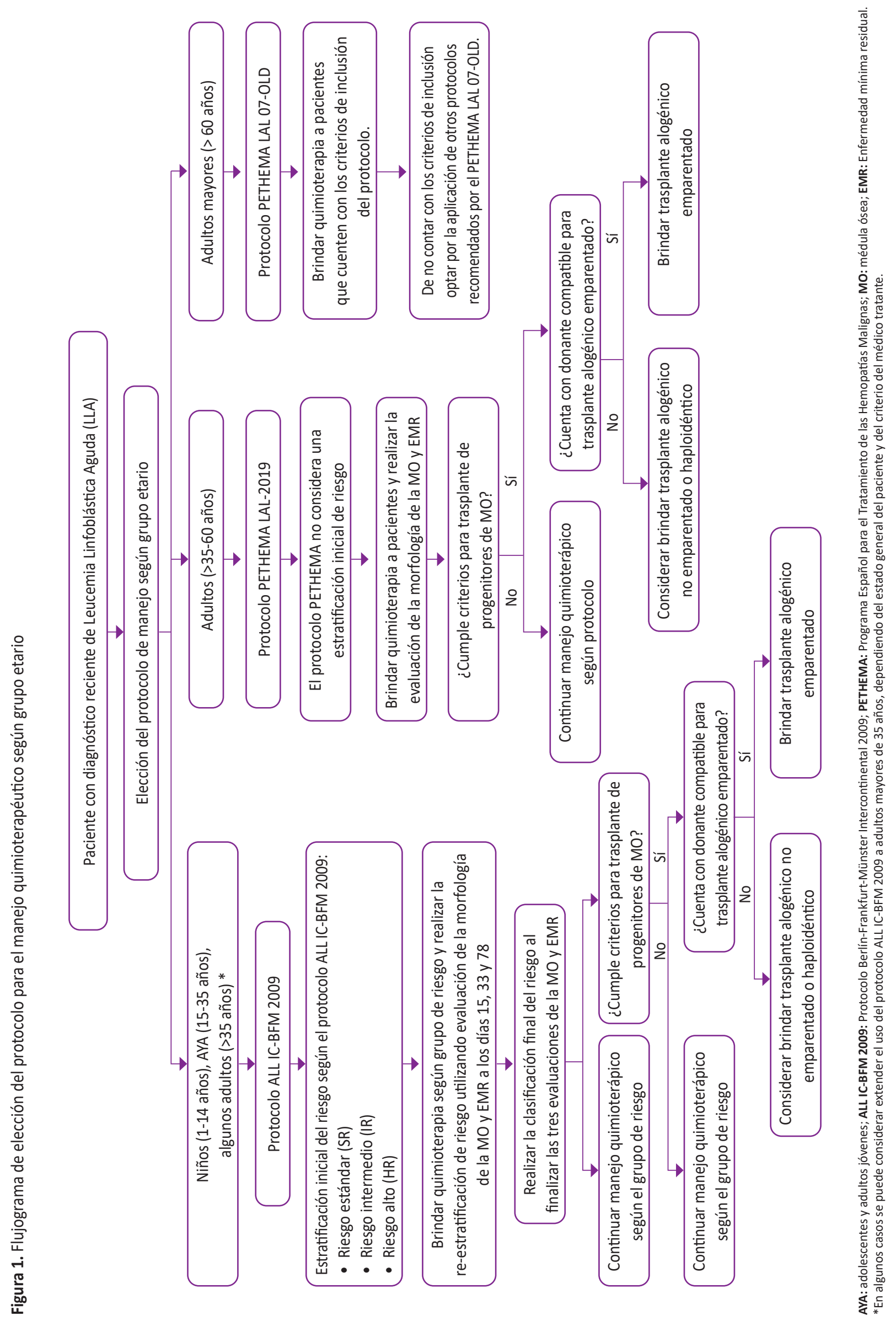


BPC-1.3: La medición de la EMR mediante citometría de flujo (CMF) tiene una sensibilidad que hace posible detectar los puntos de corte sobre la EMR propuestos por el protocolo AIEOP-BFM 2009, siempre y cuando el operador tenga la experticia necesaria ${ }^{[19]}$. Por ello, se estableció que la medición de la EMR sea realizada con el método de citometría de flujo, siendo necesaria la capacitación del personal que realice el método.

BPC-1.4: Debido a que el protocolo AIEOP-BFM 2009 incluía dentro de sus criterios de trasplante los puntajes de la EMR, el GEG consideró unificar las indicaciones de trasplante de precursores hematopoyéticos de médula ósea propuestas por los protocolos ALL IC-BFM 2009 y AIEOP-BFM 2009.

Pregunta 2: En adolescentes y adultos jóvenes (15 a 35 años) con leucemia linfoblástica aguda, ¿qué protocolo de manejo se debería usar?

\section{Rec-2.1:}

Los adolescentes y adultos jóvenes son un grupo de transición etaria, por lo que resulta difícil incluirlos dentro de los protocolos de manejo "pediátricos" y "para adultos" [20].

Para contestar esta pregunta, se contó con la RS de Ram et al., (2012) ${ }^{[21]}$, el cual incluyó 11 estudios observacionales ( $n=2489$ ), con una población de pacientes con LLA adolescentes y adultos jóvenes (16 a 35 años), y en donde se comparó la efectividad del uso de los regímenes de quimioterapia inspirados en protocolos pediátricos comparados con los protocolos para adultos. Se encontró que aquellos pacientes tratados con protocolos "pediátricos" lograron una mayor reducción de la mortalidad (RR: 0.58, IC95\%: 0.51-0.67), mayor remisión completa post inducción (RR 1.05, IC95\% 1.01-1.10), mayor supervivencia libre de eventos (RR: 1.66, IC95\%: 1.39-1.99), y menor recaída (RR 0.51, IC95\%: 0.39-0.66), en comparación con los pacientes tratados con protocolos "para adultos". Sin embargo, no se observó diferencia entre las tasas de mortalidad no relacionadas a recaída entre ambos grupos (RR: 0.53, IC95\%: 0.19-1.48) ${ }^{[21]}$. Por ello, se decidió formular una recomendación a favor del uso de protocolos pediátricos.

Aunque la certeza de la evidencia para todos los desenlaces fue muy baja, los beneficios potenciales fueron considerados muy importantes. Por este motivo, se decidió asignarle una fuerza fuerte a esta recomendación.

BPC-2.1, 2.2, 2.3 y 2.4: El GEG tomó en cuenta lo discutido en la pregunta 1 para emitir estos puntos de BPC.

BPC-2.5: El GEG consideró que el uso del protocolo ALL IC-BFM 2009 podría extender a los pacientes de 35 a 40 años, tomando en cuenta su estado general y el criterio del médico tratante. Esto en base a que la RS de Ram et al., (2012) incluía a tres estudios con poblaciones en este rango de edades (15-55 años), en los que se encontró beneficio del uso de protocolos "pediátricos" [21].
Pregunta 3: En pacientes adultos (36 a 60 años) y adultos mayores (61 años a más) con leucemia linfoblástica aguda, ¿qué protocolo de manejo se debería usar?

La búsqueda realizada no encontró evidencia de calidad para responder a esta pregunta. Por ello, se formuló puntos de BPC.

BPC-3.1: Entre los protocolos más conocidos para el manejo de adultos con LLA se encuentran: el "Hyperfractionated cyclophosphamide, vincristine, doxorubicin and dexamethasone protocol" (Hyper-CVAD), "Medical Research Council United Kingdom Acute Lymphoblastic Leukaemia XII/Eastern Cooperative Oncology Group" (MRC UKALL XII/ECOG E2993), "German Multicenter Study Group for Adult ALL" (GMALL) y el protocolo del "Programa Español para el Tratamiento de las Hemopatías Malignas" (PETHEMA) ${ }^{[22]}$.

Los estudios derivados de cada uno de estos protocolos muestran similares frecuencias de remisión completa (92\%, 91\%, 89\%, y $82 \%$, respectivamente) y supervivencia global $(38 \%, 38 \%, 54 \%$, y $34 \%$, respectivamente) ${ }^{[23]}$. Por este motivo el GEG consideró que podría utilizarse cualquiera de estos protocolos; sin embargo, se priorizo el protocolo del grupo PETHEMA, en su última versión (LAL-19), debido a que se cuenta con experiencia en su uso, se cuenta con los quimioterápicos propuestos para el manejo, y es una de las opciones propuestas para el manejo de adultos con LLA en Latinoamérica ${ }^{[24]}$.

BPC-3.2: El protocolo PETHEMA LAL-19 incorpora la evaluación de la enfermedad mínima residual (EMR) para decidir la conducta terapéutica a brindar. Debido a los resultados beneficiosos observados en el uso de la EMR en la población pediátrica ${ }^{[17]}$, y que la EMR es incorporada dentro del protocolo elegido para la población adulta, se decidió realizar la evaluación de la EMR utilizando los puntos de corte propuestos por el protocolo PETHEMA LAL-19 mediante el método de citometría de flujo.

BPC-3.3: Se consideró que las indicaciones de trasplante de precursores hematopoyéticos tenían que ir acorde a lo propuesto por el protocolo PETHEMA LAL-19.

BPC-3.4: Los protocolos más conocidos para el manejo de adultos mayores con LLA son: "Vincristine and doxorubicin plus intermittent high-dose dexamethasone régimen" (VAD), "Cancer and Leukemia Group B" (CALGB), GMALL y el protocolo "PETHEMA para el Tratamiento de la Leucemia Linfoblástica Aguda con cromosoma Filadelfia negativo en pacientes de edad avanzada" (PETHEMA LAL-07 OLD) ${ }^{[22]}$. Debido a que no se encontraron estudios que comparen la eficacia de los protocolos para el manejo del paciente adulto mayor con LLA, y que se consideró que la supervivencia global fue similar entre los protocolos mencionados: $10 \%$ a tres años ${ }^{[25]}, 17 \%$ a tres años [26] $, 3,4 \%$ a cinco años ${ }^{[27]}, 39 \%$ a dos años ${ }^{[24]}$, respectivamente; se concluyó que podría utilizarse cualquiera de estos. Sin embargo, se optó por elegir el protocolo del grupo PETHEMA LAL-07 OLD ${ }^{[28]}$ debido a que se cuenta con experiencia en su uso y se cuenta con los quimioterápicos propuestos para el manejo (con 
Figura 2. Flujograma de proceso de re-estratificación del riesgo con EMR y morfología de médula ósea en niños, adolescentes y adultos jóvenes

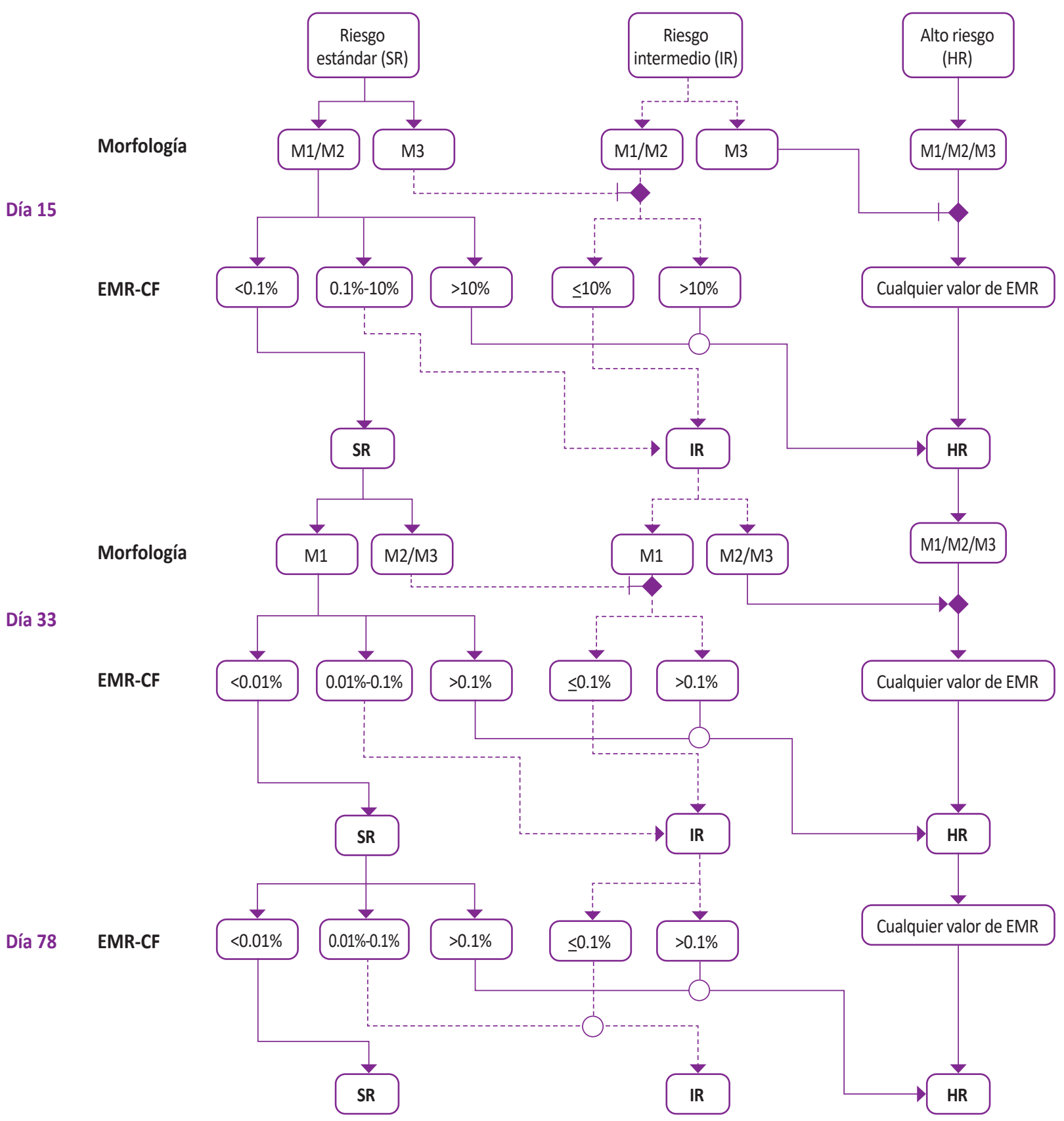

Morfología: Evaluación morfológica de la médula ósea (MO); EMR-CF: Evaluación de la enfermedad mínima residual (EMR) mediante citometría de flujo; M1: presencia de < de 5\% de blastos en MO; M2: presencia de > 5\% de blastos a < 25\% de blastos en MO; M3: presencia de $\geq 25 \%$ de blastos en MO.

la consideración del uso de idarubicina, la cual fue sustituida por daunorubicina).

Pregunta 4: En pacientes con leucemia linfoblástica aguda, ¿cuándo debería realizarse la primera punción lumbar para para profilaxis y/o diagnóstico de infiltración al sistema nervioso central?

La búsqueda realizada no encontró evidencia de calidad para responder a esta pregunta. Por ello, se formuló puntos de BPC.
BPC-4.1: La incidencia de infiltración positiva al SNC parece ser menor en los pacientes que reciben la primera punción lumbar siete días luego de iniciar el manejo con corticoides (1,1\% y $2,9 \%)^{[29,30]}$, en comparación aquellos que la reciben el primer día de quimioterapia $(14,7 \%, 38,8 \% \text {, y } 27,9 \%)^{[30]}$. Sin embargo, la supervivencia libre de eventos parece ser similar en los pacientes que reciben la punción después de una semana del inicio de los corticoides ( $84,2 \%$ y $78,2 \%)$, en comparación quienes la reciben el primer día de tratamiento $(79 \%, 80,2 \% \text {, y } 85,6 \%)^{[30,31]}$. Por 
estos motivos, se decidió realizar la primera punción lumbar en los primeros siete días luego de haber iniciado la prefase con prednisona en aquellos pacientes sin síntomas neurológicos sugestivos de infiltración al SNC, preferentemente en el día siete de haber iniciado prednisona (día ocho de tratamiento). Así mismo, se consideró importante incorporar lo mencionado en el protocolo ALL IC-BFM 2009 con respecto a la realización de tres terapias intratecales profilácticas en caso no se encuentre infiltración al SNC.

BPC-4.2: El GEG consideró que, debido a la factibilidad, en aquellos pacientes con síntomas neurológicos sugestivos de infiltración se deba realizar la primera punción lumbar para el diagnóstico de infiltración al SNC el primer día en que se inicie la prefase con prednisona.

Pregunta 5: En pacientes con leucemia linfoblástica aguda con riesgo intermedio 0 alto que se encuentren en fase de consolidación temprana con el protocolo ALL IC-BFM 2009, ¿se debería utilizar el protocolo IB de intensidad aumentada o el de intensidad estándar?

\section{Rec-5.1 y Rec-5.2:}

El protocolo de investigación ALL IC-BFM 2009 tiene entre sus objetivos comparar el protocolo IB estándar versus un protocolo IB de intensidad aumentada ${ }^{[17]}$.

Para definir cuál de estos protocolos IB usar en nuestra población, se seleccionaron tres ECA que respondieron a esta pregunta. El ECA de Nachman et al., (1988) realizado en niños con LLA de alto riesgo con respuesta inicial lenta $(n=311)$, encontró que el protocolo IB de régimen aumentado a comparación con el régimen estándar tuvo una mejor supervivencia global a los cinco años y una mayor toxicidad, como reacción alérgica a la asparaginasa nativa, mucositis y osteonecrosis [32]. El ECA de Hasting et al., (2015) realizado en niños con LLA de alto riesgo con respuesta inicial rápida $(n=1302)$, halló que los pacientes tratados con el protocolo IB de régimen aumentado tuvieron mejor supervivencia global a los cinco años en comparación con aquellos tratados con el protocolo IB de régimen estándar ${ }^{[33]}$. El ECA de Chang et al., (2008), realizado en adultos (19 a 70 años) con LLA $(n=29)$, encontró que el uso del protocolo IB de régimen aumentado versus el estándar no presentaron diferencias significativas en la supervivencia global, supervivencia libre de eventos, pero se observó una menor cantidad de pacientes que lograron completar el régimen quimioterápico con el régimen aumentado, principalmente por recaída y toxicidad ${ }^{[34]}$.

En la población pediátrica se concluyó que el protocolo IB de intensidad aumentada parece mejorar la sobrevida en pacientes pediátricos con LLA de alto riesgo, pero con una mayor toxicidad, siendo el evento más frecuente la reacción alérgica a la asparaginasa nativa. Considerando que, en nuestro contexto, se reporta gran porcentaje de pacientes que presentan reacciones alérgicas a la asparaginasa nativa, produciendo una interrupción de la quimioterapia; que los pacientes peruanos tienen un estado nutricional diferente a los que participaron en los estudios presentados ${ }^{[35]}$, conllevando a un mayor riesgo y frecuencia de toxicidad a la terapia; y existen estudios observacionales en poblaciones latinoamericanas con características similares a la peruana que reportan menos supervivencia en pacientes que utilizaron IB de intensidad aumentada ${ }^{[36]}$; el GEG concluyó en brindar una recomendación a favor del uso del protocolo IB estándar. Debido a que la certeza de la evidencia para todos los desenlaces muy baja, se decidió asignarle una fuerza condicional a esta recomendación.

Por otro lado, en población adulta, se consideró que el protocolo IB de régimen aumentado no ha mostrado tener beneficios y además presenta mayor riesgo de toxicidad, lo cual podrían presentarse aún con mayor severidad y frecuencia en los pacientes peruanos. Tomando en cuenta que la intervención tendría más riesgos y ningún beneficio en la sobrevida, se decidió formular una recomendación a favor del uso de un protocolo IB de régimen estándar para el tratamiento de adultos con LLA. Puesto que no se cuenta con beneficios claros de implementar un régimen intensivo, se decidió asignarle una fuerza fuerte a esta recomendación.

Pregunta 6: En pacientes con leucemia linfoblástica aguda de linaje $B$ con riesgo intermedio que se encuentren en fase de consolidación con el protocolo ALL IC-BFM 2009, ¿qué dosis de metotrexato se debería administrar?

La búsqueda realizada no encontró evidencia de calidad para responder a esta pregunta. Por ello, se formuló puntos de BPC.

BPC-6.1: El protocolo de investigación ALL IC-BFM 2009 tiene entre sus objetivos determinar la mejor dosis de metotrexato $\left(2000 \mathrm{mg} / \mathrm{m}^{2} /\right.$ día vs $5000 \mathrm{mg} / \mathrm{m}^{2} /$ día como dosis total administradas por día de metotrexato) para pacientes con riesgo intermedio de linaje $B^{[17]}$. Una cohorte de pacientes colombianos con LLA de linaje $B$ y $T$ de riesgo estándar e intermedio ( $N=119$ ) que recibían el protocolo ALL IC-BFM 2009, usó dosis de metotrexato de $2000 \mathrm{mg} / \mathrm{m}^{2} /$ día y $5000 \mathrm{mg} / \mathrm{m}^{2} /$ día, sin realizar comparaciones, encontrándose una supervivencia global y libre de eventos de $79,9 \%$ y $73,3 \%$, respectivamente ${ }^{[36]}$.

El GEG consideró que, la supervivencia fue similar, y que en nuestro contexto, no se alcanzaría la dosis terapéutica al utilizar dosis de $2000 \mathrm{mg} / \mathrm{m}^{2}$, tomando en cuenta que se ha reportado variantes genéticas que podrían afectar el transporte de metotrexato en una población similar a la peruana ${ }^{[3]}$. Por lo que se decidió proponer el uso de una dosis de $5000 \mathrm{mg} / \mathrm{m}^{2}$ de metotrexato en nuestra población.

Pregunta 7: En pacientes con leucemia linfoblástica aguda y cromosoma Filadelfia positivo $(\mathrm{Ph}+)$, ¿se debería brindar el Inhibidor de la Tirosina-Cinasa (TKI) imatinib?

\section{$\operatorname{Rec} 7.1:$}

El protocolo ALL IC-BFM 2009 no incluye indicaciones específicas sobre el uso de TKI, por lo que se decidió formular una pregunta al respecto. 
Figura 3. Flujograma de estratificación y manejo inicial de leucemia linfoblástica aguda en adultos y adultos mayores

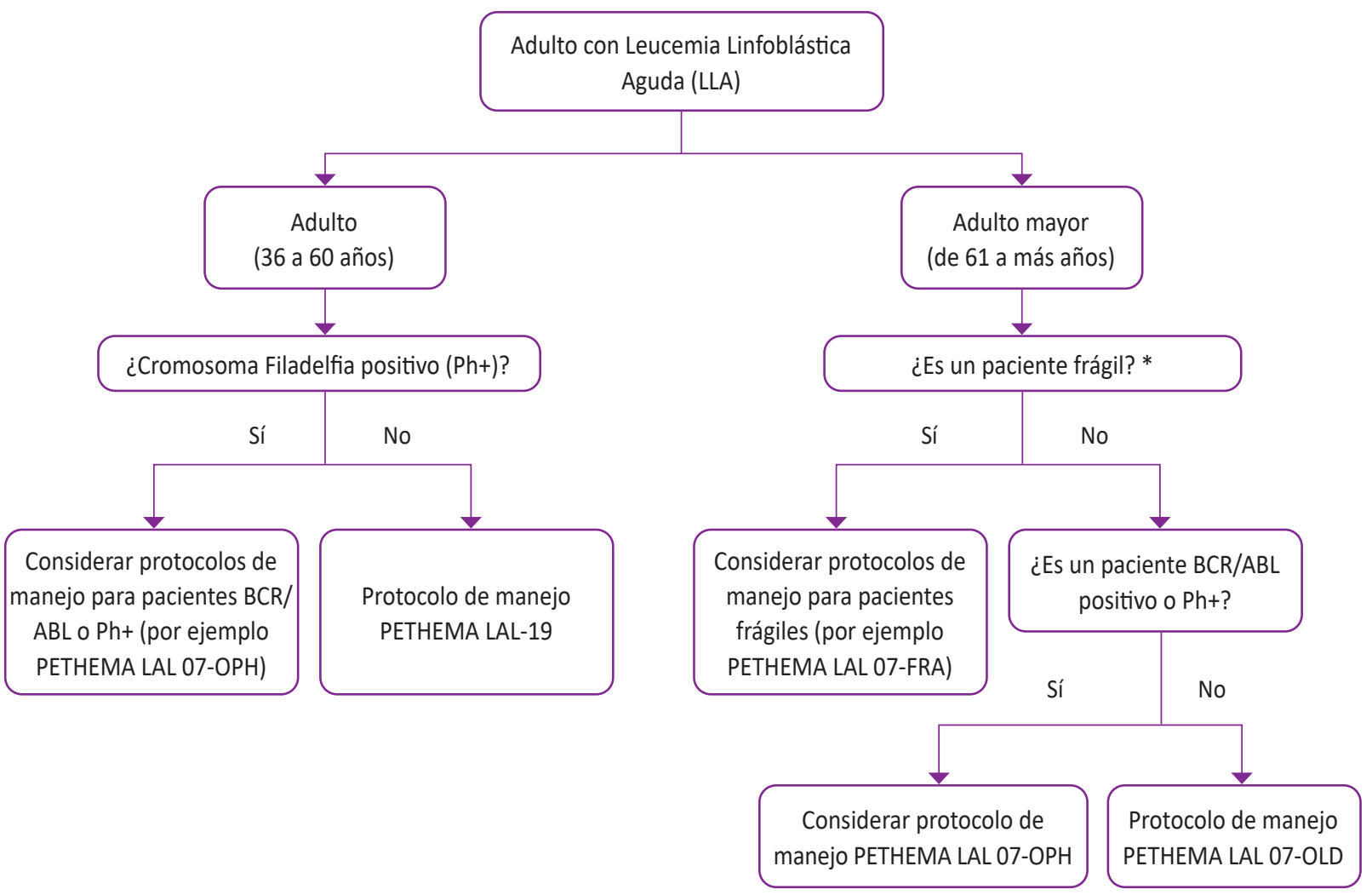

PETHEMA: Programa Español para el Tratamiento de las Hemopatías Malignas; Ph+: Cromosoma Filadelfia positivo. *El grupo PETHEMA define a un paciente frágil en base al índice de comorbilidades de Charlson.

Para responder esta pregunta se encontró el ECA de Biondi et al., (2012), el cual incluyó pacientes de 1 a 18 años de edad con LLA $\mathrm{Ph}+$, y comparó los grupos que recibieron y no recibieron imatinib en las fases post-inducción. Se encontró que la supervivencia libre de enfermedad a los cuatro años, en el análisis "as treated" fue mayor en el grupo con imatinib en comparación con el grupo que no lo recibió ( $75,2 \%$ vs $55,9 \% ; p=0,060)$; sin embargo, no se encontró diferencias significativas en el análisis "intention to treat" para este desenlace $(72,9 \% \text { vs } 61,7 \% ; p=0,240)^{[38]}$.

El GEG consideró que, si bien en el análisis "intention to treat" no encontró diferencia significativa entre la sobrevida libre de eventos, la diferencia de $11,2 \%$ entre ambos grupos, fue considerado clínicamente importante, por lo que se decidió formular una recomendación a favor del uso de imatinib. Aunque sólo se contó con un ECA para esta recomendación, las cohortes de los distintos protocolos de manejo quimioterapéutico en pacientes $\mathrm{Ph}+$ respaldan las conclusiones del ECA evaluado ${ }^{[39,40]}$, por ello, se decidió asignarle una fuerza fuerte a esta recomendación.

BPC-7.1: Sobre la dosis de imatinib a administrar en pacientes de 1 a 18 años, el ECA evaluado usaba un rango de dosis de 260-570 mg/m²/día ${ }^{[38]}$. Por lo que el GEG consideró utilizar la dosis de $340 \mathrm{mg} / \mathrm{m}^{2} /$ día por vía oral, debido a que está en el rango establecido y por ser la dosis que usualmente se administra en nuestro contexto.

BPC-7.2: Asimismo, en pacientes adultos se consideró tomar en cuenta los estudios encontrados por la revisión sistemática

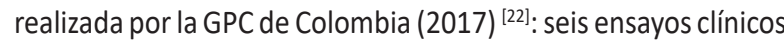
de fase I y fase II, los cuales sugieren que los TKI serían útiles en el manejo de adultos con LLA. En base a ello, se decidió establecer en adultos el uso de imatinib de 600 a $800 \mathrm{mg} /$ día vía oral de manera conjunta a la quimioterapia, como lo indica la GPC de Colombia 2017.

Pregunta 8: En pacientes con LLA en remisión completa candidatos a trasplante de células madre hematopoyéticas, en los que no se encuentra disponible el trasplante alogénico emparentado idéntico ¿Se debería brindar trasplante alogénico no emparentado o trasplante haploidéntico?

\section{Rec-8.1:}

Aproximadamente, dos tercios de los pacientes con indicación de trasplante no cuentan con un donador emparentado idéntico disponible, por lo que el trasplante de un donador no emparentado (MUD) sería la siguiente elección ${ }^{[41]}$; sin embargo, en Perú, la búsqueda de donantes idénticos no emparentado 
es realizada en banco internacionales, con una probabilidad de encontrar un donante de $25 \%$ en un periodo entre tres a seis meses. Lo que conllevaba a la demora en la realización del procedimiento y por consiguiente un mayor riesgo de recaídas ${ }^{[42]}$. Frente a esto, se ha sugerido el uso de trasplante haploidéntico, que no necesita un donante que sea HLA-idéntico al del paciente sino basta con que tenga un solo haplotipo idéntico lo que brinda una posibilidad de encontrar un donante potencial dentro de los miembros de la familia ${ }^{[43]}$.

Para responder esta pregunta se seleccionó la RS de Yang et al., (2019) ${ }^{[44]}$ que comparó el trasplante haploidentico con el trasplante MUD en la población de pacientes con algún cáncer hematológico, incluyendo las leucemias agudas; e incluyó cinco cohortes. Al actualizar la búsqueda de esta RS se encontró tres cohortes adicionales ${ }^{[45-47]}$ y se decidió realizar un meta-análisis con ocho cohortes ${ }^{[45-52]}$.

El metaanálisis reportó que el grupo que recibió trasplante haploidéntico (en comparación con aquellos que recibieron el trasplante MUD) tuvo una menor mortalidad sin recidiva (HR: 0,77; IC95\% 0,65 - 0,92), menor riesgo de enfermedad injerto huésped aguda tanto para el estadio II-IV (HR: 0,65; IC95\% 0,53 -0,81) como para el estadio III-IV (HR: 0,67; IC95\% 0,46-0,96), menor riesgo de enfermedad injerto huésped crónica (HR: 0,49; IC95\% 0,39-0,63), menor supervivencia global (HR: 0,89; IC95\% 0,80-0,99) y supervivencia libre de enfermedad (HR: 0,85; IC95\% 0,75-0,96). Asimismo, no se encontró diferencias estadísticamente significativas en el número de recaídas (HR: 0,97; IC95\% 0,85-1,10).

Considerando que el trasplante haploidéntico parece ser inferior en algunos desenlaces críticos (supervivencia global y supervivencia libre de enfermedad) en comparación con el trasplante no emparentado, pero que el trasplante haploidéntico puede ser realizado dentro de la institución (lo que acelera el proceso, evitando recaídas y generando menores gastos). Se decidió formular una recomendación a favor de cualquiera de ambos tipos de trasplantes, de no contarse con un donador emparentado idéntico. Debido a que la certeza fue muy baja, se decidió asignarle una fuerza condicional a esta recomendación.

BPC-8.1: Si bien estudios previos no han encontrado diferencias en la supervivencia libre de progresión entre el acondicionamiento mieloablativo y el de intensidad reducida ${ }^{[53]}$, el GEG consideró que podría existir mayor toxicidad terapéutica con el uso del acondicionamiento mieloablativo, por lo cual la indicación de un tipo de acondicionamiento sobre otro dependerá de la valoración médica del estado del paciente.

BPC-8.2: Dentro de los estudios incluidos en el metaanálisis, la ciclofosfamida es la profilaxis más usada para la enfermedad injerto contra huésped en el trasplante haploidentico, y es una medida disponible dentro de la realidad de EsSalud. En ese sentido, se indica utilizar un ciclo de ciclofosfamida 50mg/ kg por día en el periodo de dos días, según indicaciones internacionales ${ }^{[54]}$.
Agradecimientos: Agradecemos a Nicole Villagaray Pacheco (estudiante de la Universidad Nacional Mayor de San Marcos) y a Maribel Molina Almanza (médico hematóloga del Hospital Nacional Arzobispo Loayza) por su colaboración en las búsquedas sistemáticas y revisión de la presente GPC.

Contribuciones de autoría: Todos los autores participaron en la realización de la guía. Wendy Nieto-Gutierrez y Sergio Goicochea-Lugo se encargaron de las búsquedas sistemáticas, la evaluación de calidad de los estudios y la evaluación de la certeza de la evidencia para cada pregunta. Franko García Solórzano y Wendy Nieto-Gutierrez redactaron la primera versión del artículo. Todos los autores participaron en la discusión de los estudios encontrados y la formulación de recomendaciones y puntos de buenas prácticas clínicas. Todos los autores revisaron y aprobaron la versión final del artículo.

Potenciales conflictos de interés: Los responsables de la elaboración del presente documento declaran no tener ningún conflicto de interés financiero o no financiero, con relación a los temas descritos en el presente documento.

Fuentes de financiamiento: Este documento técnico ha sido financiado por el Instituto de Evaluación de Tecnologías en Salud e Investigación (IETSI) del Seguro Social del Perú (EsSalud).

\section{ORCID}

Ninoska Rojas Soto, https://orcid.org/0000-0003-2607-2793

Mariela Moreno Larrea, https://orcid.org/0000-0002-7653-5701

Marlies Pizarro Perea, https://orcid.org/0000-0001-7109-3660

Lourdes Aranda Gomero, https://orcid.org/0000-0001-6387-1987

Cecilia Arteta Altamirano, https://orcid.org/0000-0002-3966-0642

Renee Eyzaguirre Zapata, https://orcid.org/0000-0003-3527-7272

Sergio Goicochea-Lugo, https://orcid.org/0000-0002-0487-5547

Wendy Nieto-Gutiérrez, https://orcid.org/0000-0001-8012-1520

Franko O. García-Solorzano, https://orcid.org/0000-0002-0146-3571

Álvaro Taype-Rondan, https://orcid.org/0000-0001-8758-0463

Raúl Timaná Ruiz, https://orcid.org/0000-0003-0693-3445

\section{REFERENCIAS BIBLIOGRAFICAS}

1. Swerdlow S, Campo E, Harris N, Jaffe E, Pileri S, Stein H, et al. WHO Classification of Tumours of Haematopoietic and Lymphoid Tissues [Internet]. 2. ${ }^{\text {a }}$ ed. Washington DC: OMS; 2017 [citado 21 de marzo de 2021]. Disponible en: https://publications.iarc.fr/ Book-And-Report-Series/Who-Classification-Of-Tumours/WHOClassification-Of-Tumours-Of-Haematopoietic-And-LymphoidTissues-2017

2. Redaelli A, Laskin BL, Stephens JM, Botteman MF, Pashos CL. A systematic literature review of the clinical and epidemiological burden of acute lymphoblastic leukaemia (ALL). Eur J Cancer Care (EngI). 2005;14(1):53-62. doi:10.1111/j.1365-2354.2005.00513.x

3. Dores GM, Devesa SS, Curtis RE, Linet MS, Morton LM. Acute leukemia incidence and patient survival among children and adults in the United States, 2001-2007. Blood. 2012;119(1):34-43. doi:10.1182/blood-2011-04-347872 
4. Katz AJ, Chia VM, Schoonen WM, Kelsh MA. Acute lymphoblastic leukemia: an assessment of international incidence, survival, and disease burden. Cancer Causes Control. 2015;26(11):1627-42. doi:10.1007/s10552-015-0657-6

5. Centro Nacional de Epidemiologia Epidemiología, Prevención y Control de Enfermedades. Boletín Epidemiológico (Lima) $\mathrm{N}^{\circ}$ 32 (03 al 09 de Agosto del 2014) [Internet]. CDC-MINSA; 2014. Disponible en: http://www.dge.gob.pe/portal/docs/vigilancia/ boletines/2014/32.pdf

6. Santillan GAH, Renee Eyzaguirre Zapata, Zuloeta JS. Neutropenia febril posterior a quimioterapia de consolidación en pacientes pediátricos con leucemia linfoblástica aguda del Hospital Nacional Guillermo Almenara Irigoyen durante 2008-2010. Revista del Cuerpo Médico Hospital Nacional Almanzor Aguinaga Asenjo. 2011;4(2):99-102

7. Schrappe M, Beck J, Brandeis WE, Feickert H-J, Gadner H, Graf N, et al. Die Behandlung der akuten lymphoblastischen Leukämie im Kindes- und Jugendalter: Ergebnisse der multizentrischen Therapiestudie ALL-BFM 81*. Klin Padiatr. 1987;199(3):133-50. doi:10.1055/s-2008-1026780

8. Cancer Research UK. Survival | Acute lymphoblastic leukaemia (ALL) [Internet]. 2018 [citado 20 de septiembre de 2019]. Disponible en: https://www.cancerresearchuk.org/about-cancer/acutelymphoblastic-leukaemia-all/survival

9. Möricke A, Reiter A, Zimmermann M, Gadner H, Stanulla M, Dördelmann $M$, et al. Risk-adjusted therapy of acute lymphoblastic leukemia can decrease treatment burden and improve survival: treatment results of 2169 unselected pediatric and adolescent patients enrolled in the trial ALL-BFM 95. Blood. 2008;111(9):447789. doi:10.1182/blood-2007-09-112920

10. Möricke A, Zimmermann M, Reiter A, Henze G, Schrauder A, Gadner $\mathrm{H}$, et al. Long-term results of five consecutive trials in childhood acute lymphoblastic leukemia performed by the ALLBFM study group from 1981 to 2000. Leukemia. 2010;24(2):265-84. doi:10.1038/leu.2009.257

11. Castro-Arechaga S, Ronceros-Salas L, Vega-Centeno S, Moreno M, Soto A. Sobrevida global y libre de enfermedad en una cohorte peruana de pacientes con leucemia linfoblástica aguda. Revista Peruana de Medicina Experimental y Salud Publica. 2018;35(3):41624. doi:10.17843/rpmesp.2018.353.2947

12. Tello-Vera S, Colchado-Aguilar J, Carpio-Vásquez W, RodríguezGueorguiev N, Díaz-Vélez C. Supervivencia de pacientes con leucemias agudas en dos hospitales de la seguridad social del Perú. Revista Venezolana de Oncología. 2018;30(1):2-9.

13. Balshem $H$, Helfand $M$, Schünemann $H J$, Oxman AD, Kunz R, Brozek J, et al. GRADE guidelines: 3. Rating the quality of evidence. J Clin Epidemiol. 2011;64(4):401-6. doi:10.1016/j.jclinepi.2010.07.015

14. Andrews J, Guyatt G, Oxman AD, Alderson P, Dahm P, Falck-Ytter Y, et al. GRADE guidelines: 14. Going from evidence to recommendations: the significance and presentation of recommendations. J Clin Epidemiol. 2013;66(7):719-25. doi:10.1016/j.jclinepi.2012.03.013

15. Pui $\mathrm{C}-\mathrm{H}$, Evans WE. Treatment of acute lymphoblastic leukemia. $\mathrm{N}$ Engl J Med. 2006;354(2):166-78. doi:10.1056/NEJMra052603

16. Hunger SP, Mullighan CG. Acute Lymphoblastic Leukemia in Children. N Engl J Med. 2015;373(16):1541-52. doi:10.1056/NEJMra1400972

17. IC-BFM A. ALL IC-BFM 2009. A Randomized Trial of the I-BFM-SG for the Management of Childhood non-B Acute Lymphoblastic Leukemia. Final Version of Therapy Protocol from August-14-2009. [Internet]. IC-BFM A; 2009. Disponible en: https://www.bialaczka. org/wp-content/uploads/2016/10/ALLIC_BFM_2009.pdf

18. Stary J, Zimmermann M, Campbell M, Castillo L, Dibar E, Donska S, et al. Intensive chemotherapy for childhood acute lymphoblastic leukemia: results of the randomized intercontinental trial ALL IC-BFM 2002. J Clin Oncol. 2014;32(3):174-84. doi:10.1200/ JCO.2013.48.6522

19. Campana D. Minimal residual disease in acute lymphoblastic leukemia. Hematology Am Soc Hematol Educ Program. 2010;2010(2010):7-12. doi:10.1182/asheducation-2010.1.7

20. Chiaretti S, Jabbour E, Hoelzer D. «Society of Hematologic Oncology (SOHO) State of the Art Updates and Next Questions»-Treatment of ALL. Clin Lymphoma Myeloma Leuk. 2018;18(5):301-10. doi:10.1016/j.clml.2018.03.014

21. Ram R, Wolach O, Vidal L, Gafter-Gvili A, Shpilberg O, Raanani P. Adolescents and young adults with acute lymphoblastic leukemia have a better outcome when treated with pediatric-inspired regimens: systematic review and meta-analysis. Am J Hematol. 2012;87(5):472-8. doi:10.1002/ajh.23149

22. Ministerio de Salud y Protección Social, COLCIENCIAS, Instituto Nacional de Cancerología-ESE. Guía de Práctica Clínica para la detección, tratamiento y seguimiento de leucemias linfoblástica y mieloide en población mayor de 18 años. [Internet]. Bogota: COLCIENCIAS; 2017. Disponible en: http://gpc.minsalud. gov.co/gpc_sites/Repositorio/Conv_563/GPC_Leucemia_ Mayores_18a\%C3\%B1os/GPC_Leucemias.pdf

23. Gökbuget N, Hoelzer D. Treatment of adult acute lymphoblastic leukemia. Semin Hematol. 2009;46(1):64-75. doi:10.1053/j. seminhematol.2008.09.003

24. Sancho J-M, Ribera J-M, Xicoy B, Morgades M, Oriol A, Tormo $\mathrm{M}$, et al. Results of the PETHEMA ALL-96 trial in elderly patients with Philadelphia chromosome-negative acute lymphoblastic leukemia. Eur J Haematol. 2007;78(2):102-10. doi:10.1111/j.16000609.2006.00778.x

25. Kantarjian HM, O'Brien S, Smith T, Estey EH, Beran M Preti $A$, et al. Acute lymphocytic leukaemia in the elderly: characteristics and outcome with the vincristine-adriamycindexamethasone (VAD) regimen. Br J Haematol. 1994;88(1):94-100. doi:10.1111/j.1365-2141.1994.tb04982.x

26. Larson RA, Dodge RK, Linker CA, Stone RM, Powell BL, Lee EJ, et al. A randomized controlled trial of filgrastim during remission induction and consolidation chemotherapy for adults with acute lymphoblastic leukemia: CALGB study 9111. Blood. 1998;92(5):1556-64.

27. Späth-Schwalbe E, Heil G, Heimpel H. Acute lymphoblastic leukemia in patients over 59 years of age. Experience in a single center over a 10-year period. Ann Hematol. 1994;69(6):291-6. doi:10.1007/ BF01696557

28. Programa Español para el Tratamiento de las Hemopatias Malignas., Sociedad Española de Hematología y Hemoterapia. Protocolo para el tratamiento de la Leucemia Aguda Linfoblastica de alto riesgo BCR/ABL negativa en adultos. PETHEMA; 2013.

29. Manabe A, Tsuchida M, Hanada R, Ikuta K, Toyoda Y, Okimoto Y, et al. Delay of the diagnostic lumbar puncture and intrathecal chemotherapy in children with acute lymphoblastic leukemia who undergo routine corticosteroid testing: Tokyo Children's Cancer Study Group study L89-12. J Clin Oncol. 2001;19(13):3182-7. doi:10.1200/JCO.2001.19.13.3182

30. Hasegawa D, Manabe A, Ohara A, Kikuchi A, Koh K, Kiyokawa N et al. The utility of performing the initial lumbar puncture on day 8 in remission induction therapy for childhood acute lymphoblastic leukemia: TCCSG L99-15 study. Pediatr Blood Cancer. 2012;58(1):2330. doi:10.1002/pbc. 22965

31. Liu H-C, Yeh T-C, Hou J-Y, Chen K-H, Huang T-H, Chang C-Y, et al. Triple intrathecal therapy alone with omission of cranial radiation in children with acute lymphoblastic leukemia. J Clin Oncol. 2014;32(17):1825-9. doi:10.1200/JCO.2013.54.5020 
32. Nachman JB, Sather HN, Sensel MG, Trigg ME, Cherlow JM, Lukens $\mathrm{JN}$, et al. Augmented post-induction therapy for children with high-risk acute lymphoblastic leukemia and a slow response to initial therapy. N Engl J Med. 1998;338(23):1663-71. doi:10.1056/ NEJM199806043382304

33. Hastings C, Gaynon PS, Nachman JB, Sather HN, Lu X, Devidas M, et al. Increased post-induction intensification improves outcome in children and adolescents with a markedly elevated white blood cell count $(\geq 200 \times 109 /$ I) with T cell Acute Lymphoblastic Leukaemia but not B cell disease: A report from the Children's Oncology Group. Br J Haematol. 2015;168(4):533-46. doi:10.1111/bjh.13160

34. Chang JE, Medlin SC, Kahl BS, Longo WL, Williams EC, Lionberger $\mathrm{J}$, et al. Augmented and standard Berlin-Frankfurt-Munster chemotherapy for treatment of adult acute lymphoblastic leukemia. Leuk Lymphoma. 2008;49(12):2298-307. doi:10.1080/10428190802517732

35. Instituto Nacional de Estadistica e Informatica. Desnutrición crónica afectó al 12,2\% de la población menor de cinco años de edad en el año 2018 [Internet]. 2019 [citado 19 de septiembre de 2019]. Disponible en: http://m.inei.gob.pe/prensa/noticias/desnutricioncronica-afecto-al-122-de-la-poblacion-menor-de-cinco-anos-deedad-en-el-ano-2018-11370/

36. Trujillo ÁM, Linares A, Sarmiento IC, Trujillo ÁM, Linares A, Sarmiento IC. Intensive chemotherapy in children with acute lymphoblastic leukemia. Interim analysis in a referral center in Colombia. Revista de la Facultad de Medicina. 2016;64(3):417-25. doi:10.15446/revfacmed.v64n3.53961

37. Iparraguirre L, Gutierrez-Camino A, Umerez M, Martin-Guerrero I, Astigarraga I, Navajas A, et al. MiR-pharmacogenetics of methotrexate in childhood B-cell acute lymphoblastic leukemia. Pharmacogenet Genomics. 2016;26(11):517-25. doi:10.1097/ FPC.0000000000000245

38. Biondi A, Schrappe M, De Lorenzo P, Castor A, Lucchini G, Gandemer $V$, et al. Imatinib after induction for treatment of children and adolescents with Philadelphia-chromosome-positive acute lymphoblastic leukaemia (EsPhALL): a randomised, open-label, intergroup study. Lancet Oncol. 2012;13(9):936-45. doi:10.1016/ S1470-2045(12)70377-7

39. Schultz KR, Bowman WP, Aledo A, Slayton WB, Sather H, Devidas $M$, et al. Improved Early Event-Free Survival With Imatinib in Philadelphia Chromosome-Positive Acute Lymphoblastic Leukemia: A Children's Oncology Group Study. J Clin Oncol. 2009;27(31):517581. doi:10.1200/JCO.2008.21.2514

40. Lou Y, Ma Y, Li C, Suo S, Tong H, Qian W, et al. Efficacy and prognostic factors of imatinib plus CALLG2008 protocol in adult patients with newly diagnosed Philadelphia chromosome-positive acute lymphoblastic leukemia. Front Med. 2017;11(2):229-38. doi:10.1007/s11684-017-0506-y

41. Ciurea SO, Bittencourt MCB, Milton DR, Cao K, Kongtim P, Rondon $G$, et al. Is a matched unrelated donor search needed for all allogeneic transplant candidates? Blood Adv. 2018;2(17):2254-61. doi:10.1182/bloodadvances.2018021899

42. Aversa F, Berneman ZN, Locatelli F, Martelli MF, Reisner Y, Tabilio A, et al. Fourth International Workshop on Haploidentical Transplants, Naples, Italy, July 8-10, 2004. Blood Cells Mol Dis. 2004;33(3):15975. doi:10.1016/j.bcmd.2004.08.008

43. Tarín-Arzaga L del C, González-Llano Ó. Trasplante haploidéntico de células hematopoyéticas. ¿El límite de la incompatibilidad? Rev Hematol Mex. 2012;13(1):1-3.
44. Yang B, Yu R, Cai L, Bin Guo null, Chen H, Zhang $H$, et al. Haploidentical versus matched donor stem cell transplantation for patients with hematological malignancies: a systemic review and meta-analysis. Bone Marrow Transplant. 2019;54(1):99-122. doi:10.1038/s41409-018-0239-9

45. Gao L, Zhang C, Gao L, Liu Y, Su Y, Wang S, et al. Favorable outcome of haploidentical hematopoietic stem cell transplantation in Philadelphia chromosome-positive acute lymphoblastic leukemia: a multicenter study in Southwest China. J Hematol Oncol. 2015;8:90. doi:10.1186/s13045-015-0186-5

46. Han L-J, Wang Y, Fan Z-P, Huang F, Zhou J, Fu Y-W, et al. Haploidentical transplantation compared with matched sibling and unrelated donor transplantation for adults with standard-risk acute lymphoblastic leukaemia in first complete remission. Br J Haematol. 2017;179(1):120-30. doi:10.1111/bjh.14854

47. Slade M, DiPersio JF, Westervelt P, Vij R, Schroeder MA, Romee R. Haploidentical Hematopoietic Cell Transplant with Post-Transplant Cyclophosphamide and Peripheral Blood Stem Cell Grafts in Older Adults with Acute Myeloid Leukemia or Myelodysplastic Syndrome. Biol Blood Marrow Transplant. 2017;23(10):1736-43. doi:10.1016/j. bbmt.2017.06.019

48. Bashey A, Zhang X, Jackson K, Brown S, Ridgeway M, Solh M, et al. Comparison of Outcomes of Hematopoietic Cell Transplants from T-Replete Haploidentical Donors Using Post-Transplantation Cyclophosphamide with 10 of 10 HLA-A, -B, -C, -DRB1, and -DQB1 Allele-Matched Unrelated Donors and HLA-Identical Sibling Donors: A Multivariable Analysis Including Disease Risk Index. Biol Blood Marrow Transplant. 2016;22(1):125-33. doi:10.1016/j. bbmt.2015.09.002

49. Piemontese S, Ciceri F, Labopin M, Arcese W, Kyrcz-Krzemien S, Santarone S, et al. A comparison between allogeneic stem cell transplantation from unmanipulated haploidentical and unrelated donors in acute leukemia. Journal of Hematology \& Oncology. 2017;10(1):24. doi:10.1186/s13045-017-0394-2

50. Solomon SR, Sizemore CA, Zhang X, Brown S, Holland HK, Morris $\mathrm{LE}$, et al. Impact of Donor Type on Outcome after Allogeneic Hematopoietic Cell Transplantation for Acute Leukemia. Biol Blood Marrow Transplant. 2016;22(10):1816-22. doi:10.1016/j. bbmt.2016.07.010

51. Rashidi A, DiPersio JF, Westervelt P, Vij R, Schroeder MA, Cashen $A F$, et al. Comparison of Outcomes after Peripheral Blood Haploidentical versus Matched Unrelated Donor Allogeneic Hematopoietic Cell Transplantation in Patients with Acute Myeloid Leukemia: A Retrospective Single-Center Review. Biol Blood Marrow Transplant. 2016;22(9):1696-701. doi:10.1016/j.bbmt.2016.05.010

52. Ciurea SO, Zhang M-J, Bacigalupo AA, Bashey A, Appelbaum FR, Aljitawi OS, et al. Haploidentical transplant with posttransplant cyclophosphamide vs matched unrelated donor transplant for acute myeloid leukemia. Blood. 2015;126(8):1033-40. doi:10.1182/ blood-2015-04-639831

53. Abdul Wahid SF, Ismail N-A, Mohd-Idris M-R, Jamaluddin FW, Tumian N, Sze-Wei EY, et al. Comparison of reduced-intensity and myeloablative conditioning regimens for allogeneic hematopoietic stem cell transplantation in patients with acute myeloid leukemia and acute lymphoblastic leukemia: a meta-analysis. Stem Cells Dev. 2014;23(21):2535-52. doi:10.1089/scd.2014.0123

54. Champlin RE, Passweg JR, Zhang MJ, Rowlings PA, Pelz CJ, Atkinson $K A$, et al. T-cell depletion of bone marrow transplants for leukemia from donors other than HLA-identical siblings: advantage of T-cell antibodies with narrow specificities. Blood. 2000;95(12):3996-4003. 